\title{
0731. Effects of sildenafil in a porcine model of endotoxemia
}

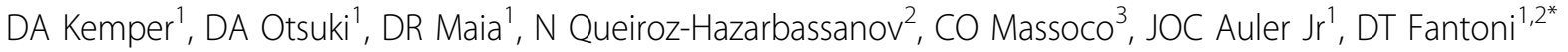 \\ From ESICM LIVES 2014 \\ Barcelona, Spain. 27 September - 1 October 2014
}

\section{Introduction}

Sepsis-induced lung injury is one of the major causes of morbidity and mortality in intensive care patients [1]. The clinical manifestations include pulmonary hypertension, formation of extravascular lung water (EVLW), and deterioration of pulmonary gas exchange. Administration of sildenafil, a selective inhibitor of isoenzyme phosphodiesterase-5, in patients with pulmonary hypertension improves oxygenation and ameliorates pulmonary hypertension [2].

\section{Objectives}

To evaluate the effect of sildenafil on endotoxin-induced lung injury in pigs.

\section{Methods}

Twenty anesthetized and mechanically ventilated pigs were randomized after baseline (BL) measurements to Control (saline solution) or Sildenafil (100mg) group. After 30 minutes of saline/sildenafil administration, all animals were submitted to a continuous lipopolysaccharide (LPS) infusion $(4 \mathrm{mcg} / \mathrm{kg} / \mathrm{min})$ until the end of study. Hemodynamics and oxygenation parameters were evaluated at BL, 30, 60, 120 and 180 minutes after LPS (LPS60, LPS120 and LPS180). Plasma cytokines (TNFalpha, IL-1beta, IL-6 and IL-10) were evaluated at BL and LPS180. The parametric data were analyzed using ANOVA for repeated measurements and nonparametric data with Kruskall-Wallis and the Mann-Whitney U test.

\section{Results}

Endotoxemia induced a significant pulmonary hypertension with more than a twofold increase in mean arterial pulmonary pressure and pulmonary vascular resistance index, and also a decrease in $\mathrm{PaO}_{2} / \mathrm{FiO}_{2}$. Mean arterial pulmonary and mean arterial pressures were significantly lower in Sildenafil group. Sildenafil improved arterial oxygen tension but also increased the shunt fraction (Figure1).

All cytokines increased after LPS infusion in both groups and no difference was observed between the animals receiving sildenafil and normal saline.

\section{Conclusions}

Sildenafil administration improved pulmonary hypertension and oxygenation in LPS-induced lung injury but increased shunt fraction and promoted systemic hypotension. It remains unclear whether sildenafil may be beneficial in sepsis patients.

Grant acknowledgment

Laboratory of Anesthesiology (LIM08), Faculdade de Medicina da Universidade de São Paulo.

\section{Authors' details}

'Faculdade de Medicina da Universidade de São Paulo, Laboratory of

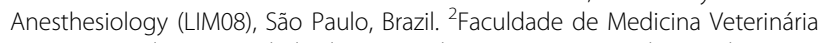
e Zootecnia da Universidade de São Paulo, Surgery, São Paulo, Brazil.

${ }^{3}$ Faculdade de Medicina Veterinária e Zootecnia da Universidade de São Paulo, Pathology, São Paulo, Brazil. 


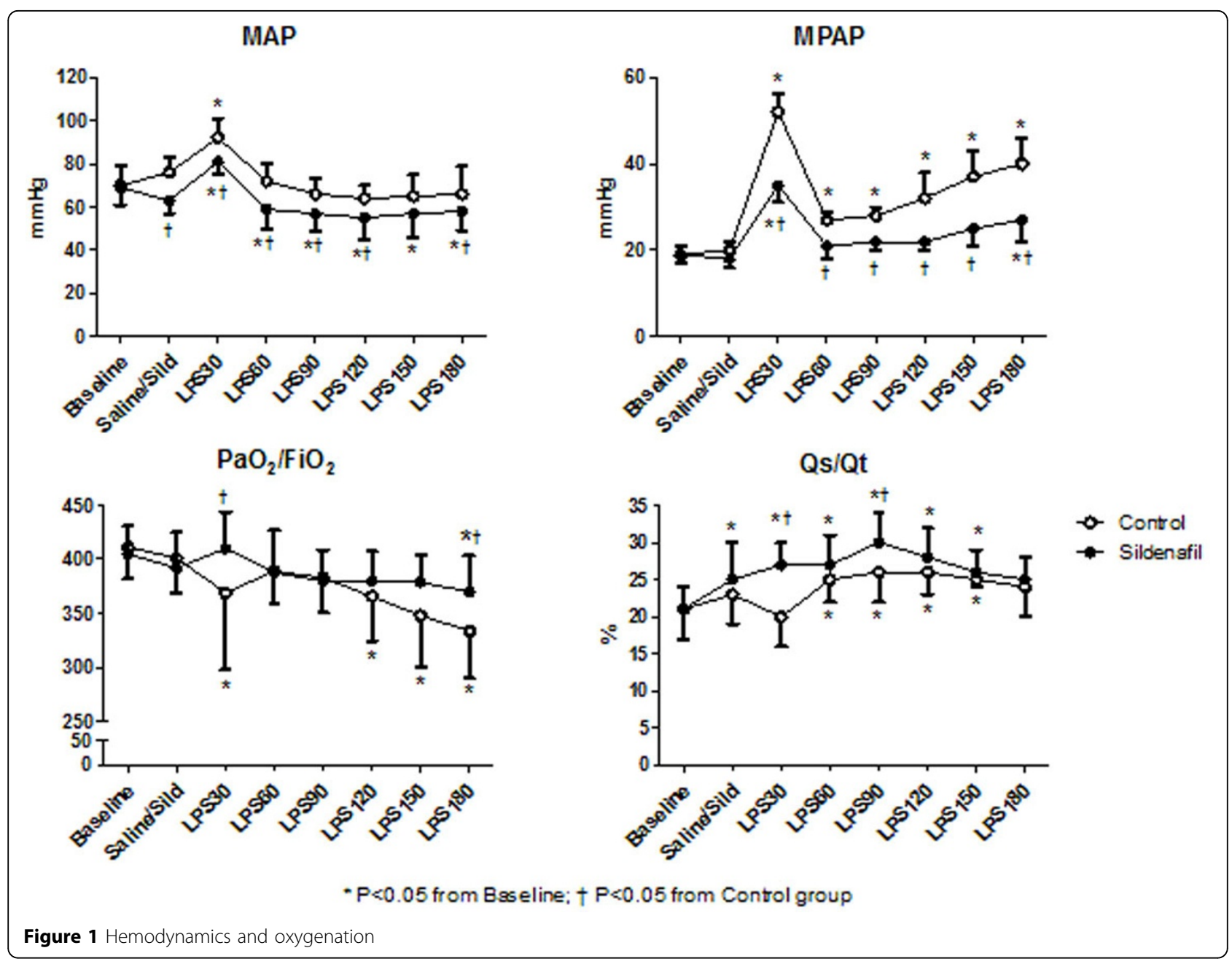

Published: 26 September 2014

\section{References}

1. Rubenfeld GD, Caldwell E, Peabody E, et al: Incidence and Outcomes of Acute Lung Injury. N Engl I Med 2005, 353:1685-93.

2. Galie N, Ghofrani HA, Torbicki A, et al: Sildenafil citrate therapy for pulmonary arterial hypertension. N Engl J Med 2005, 353:2148-57.

\section{Submit your manuscript to a SpringerOpen ${ }^{\circ}$} journal and benefit from:

- Convenient online submission

- Rigorous peer review

- Immediate publication on acceptance

- Open access: articles freely available online

- High visibility within the field

- Retaining the copyright to your article

Submit your next manuscript at $>$ springeropen.com 